\section{The American Association for Thoracic Surgery}

\section{Attend the Heart Valve Summit: Medical, Surgical, and Interventional Decision Making}

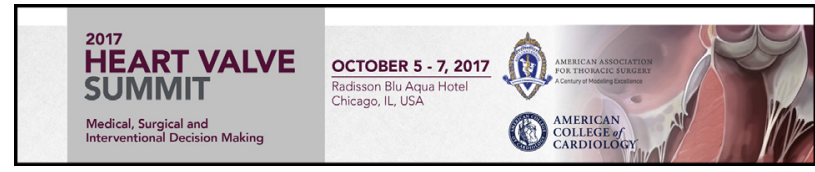

The American College of Cardiology and the The American Association for Thoracic Surgery are once again partnering to bring together cardiologists and surgeons in a cooperative, case-based course to address the rapid advances in the treatment of valvular heart disease.

October 5-7, 2017

Radisson Blu Aqua Hotel

Chicago, IL, USA

\section{Program Overview}

With the tradition of interactivity and practical decision making, the unique Heart Valve Summit is designed to engage participants in discussions, debates, and potential controversies surrounding real-world cases with renowned faculty on the cutting edge of clinically relevant data for valvular heart disease management.

This interdisciplinary course emphasizes clinical decision making while combining the most relevant medical, surgical, and interventional options for patient care. Tools for management are rapidly advancing and can significantly impact the entire care team. Breakout sessions for cardiologists, cardiac surgeons, nurses, and physician assistants are designed to help specialists manage their unique challenges from a team perspective.

\section{Heart Valve Summit Will Highlight:}

- Basics of the Aortic Valve

- Cardiac Network Trials

- Decision Making: Recurrent Mitral Valve Regurgitation

- Degenerative Mitral Anatomy and Physiology

- Difficult Choices and Scenarios

- Ischemic Mitral Regurgitation

- Mitral Endocarditis

- Mitral Valve Replacement

- Preparing for the Future in Mitral Valve Treatment

- TAVR

- The Future of Transcatheter Mitral Interventions

- Transcatheter Aortic Valve Replacement-Indications and Devices

- The Asymptomatic Patient with Advanced Valve Disease

- Treatment of Aortic Valve Disease

- Valve Disease and the Right Ventricle

\section{Course Directors}

David H. Adams

Steven F. Bolling

Robert O. Bonow

Howard C. Herrmann

\section{Nurse Planner}

Michele Mistovich

View the Program, Register, and Reserve Housing: www.aats.org/valve

\section{Save the Date: 2017 Focus on Thoracic Surgery: Mastering Surgical Innovation}

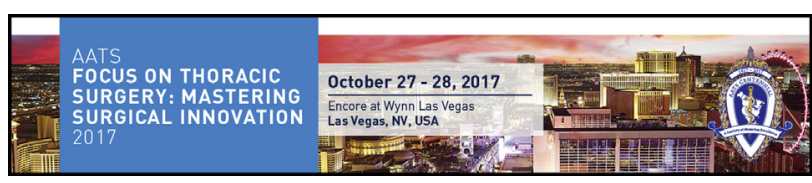

October 27-28, 2017

Encore at Wynn Las Vegas

Las Vegas, NV, USA

Program Directors

G. Alexander Patterson

David J. Sugarbaker

For more information, to go: http://aats.org/focus

Save the Date: AATS Surgical Treatment of Arrhythmias and Rhythm Disorders 2017

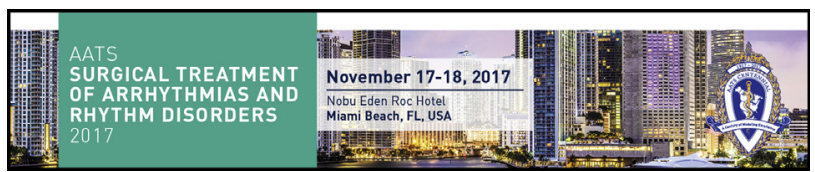

Don't miss out on this two-day, interactive forum that supports the exchange of information between electrophysiologists and surgeons.

November 17-18, 2017

Nobu Eden Roc Hotel

Miami Beach, FL, USA

\section{Program Overview}

The AATS Surgical Treatment of Arrhythmias and Rhythm Disorders provides a comprehensive, unbiased review of the surgical treatment of cardiac arrhythmias and rhythm disorders. The meeting will cover basic underlying mechanisms, cardiac recording and mapping techniques, clinical electrophysiology, operative techniques, cardiac monitoring and appropriate follow-up. The esteemed faculty will cover: Interventional approaches to atrial fibrillation, ventricular tachycardia, inappropriate sinus tachycardia, and transvenous and epicardial lead implantation and extraction techniques. 
Sessions include:

- Concomitant Ablation-How I Do It and Why

- Hybrid Ablation and Other Alternative Approaches for Lone Atrial Fibrillation

- Lead Extraction: Modern Techniques in Management of Complications

- Management of the Left Atrial Appendage

- Mechanisms of Atrial Fibrillation

- Special Issues and Controversies in Surgical Ablation

- Surgical Ablation Guidelines

- Surgical Treatment of Arrhythmias: The Basics

- Surgical Treatment of Lone Atrial Fibrillation: How I Do It

- Ventricular Tachycardia Ablation

Program Directors

Ralph J. Damiano, Jr

A. Marc Gillinov

\section{Program Committee}

Niv Ad

Vinay Badhwar

Manuel Castella

James L. Cox

Mark LaMeir

Patrick M. McCarthy

Takashi Nitta

Harold G. Roberts

Richard Schuessler

Register and Reserve Housing: www.aats.org/stars

Don't Miss the 2017 AATS International Cardiovascular Symposium

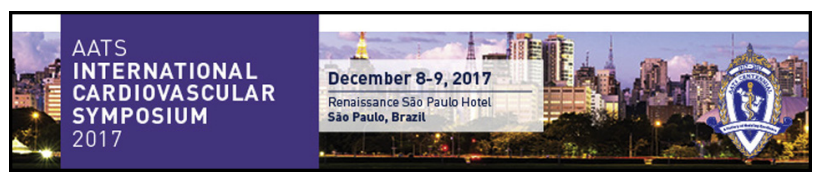

December 8-9, 2017

Renaissance São Paulo Hotel

São Paulo, Brazil

Join renowned cardiologists and surgeons at the 2017 AATS International Cardiovascular Symposium in São Paulo, Brazil, on December 8-9, 2017, to advance your clinical knowledge in heart valve disease-aortic and ascending aorta, coronary, mitral, pulmonary, and tricuspid.

The two-day symposium will bring together international leaders to discuss state-of-the-art information on devices, long-term results, and surgical techniques with a focus on preventing, diagnosing, and treating heart valve disease.

\section{Program Directors}

Joseph S. Coselli

Walter J. Gomes

Marc R. Moon

Thoralf M. Sundt III

For more information, go to: aats.org/ics

\section{AATS Mechanical Circulatory Support Symposium: 21st Century State-of-the-Art Treatment of Advanced Heart and Lung Failure}

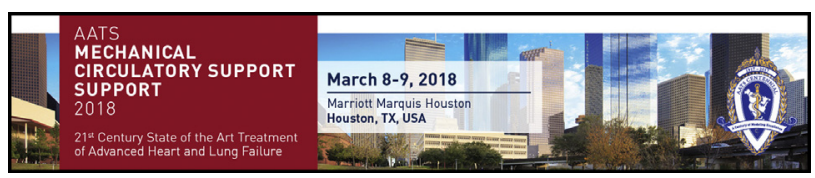

\section{SAVE THE DATE}

March 8-9, 2018

Marriott Marquis Houston

Houston, TX, USA

\section{Program Directors}

Shaf Keshavjee

Jeffrey A. Morgan

Francis D. Pagani

Mark S. Slaughter

The Mechanical Circulatory Support Symposium focuses on the 21st century state-of-the-art treatment of advanced heart and lung failure. Experts in the field will lead this two-day meeting covering mechanical circulatory support/ LVADs, ECMO, and heart and lung transplantation topics. The program is designed to bring LVAD/transplant cardiac surgeons, heart failure cardiologists, pulmonologists, anesthesiologists, and industry representatives together for much-needed discussions.

\section{Sessions Include:}

- Bridge Strategies With Short-Term Devices

- Complications Using Long-Term MC

- Controversial Topics With Long-Term Device Therapy

- ECMO for Respiratory Failure

- MCS Device Thrombosis

- Minimally Invasive LVAD Insertion, Concomitant Procedures

- Patient Selection and Optimization for Long-Term MCS Devices

- The Role of ECLS in Lung Transplantation 